\title{
A preservação da memória estudantil como proposta curricular dos cursos de Educação Física: o caso do centro de memória do Departamento de Educação Física (CEMEDEF) da UFPR
}

\author{
Elyandra Caroline Alves de Souza* \\ Andre Mendes Capraro**
}

\begin{abstract}
Resumo: Intervir na preservação da memória escolar não se resume a execução de tarefas técnicas, embora tais ações sejam necessárias num interim de valorização do patrimônio cultural produzidos pelas instituições educacionais. É essencial abarcar no planejamento para a constituição de centros de documentação, a relação com a prática docente, assim como a vivência discente. São esses os atores que produzem os acontecimentos da cultura escolar e devem ser os responsáveis pela guarda e conservação dos marcos que foram impressos na memória do contexto onde se estabeleceram. Fundamentados nessa premissa, esse artigo pretende apontar alternativas que estão sendo desenvolvidas no Centro de Memória do Departamento de Educação Física (CEMEDEF) de maneira que as intervenções possam ser avaliadas ou até mesmo subsidiar propostas para a fundação de novos centros de documentação escolar.
\end{abstract}

Palavras Chave: Memória. Escola. Interdisciplinaridade.

\section{INTRODUÇÃO}

A participação no desenvolvimento de um centro de documentação, caracterizado como centro de memória, trouxe o contato com novas problemáticas, que por sua vez, suscitaram o aprofundamento teórico-técnico dos conteúdos que estão inseridos nas rotinas desses espaços. Percebeu-se ser pertinente registrar as

\footnotetext{
'Mestranda.Educacao Fisica. Universidade Federal do Paraná (UFPR). Curitiba, PR, Brasil. Email: elyandraalves@hotmail.com

"Doutor em História. Universidade Federal do Paraná (UFPR). Curitiba, PR, Brasil. E-mail: andrecapraro@onda.com.br
} 
transformações que ocorrem na estrutura do centro, ainda que de maneira apenas descritiva. Todas as atividades foram listadas e refletidas para a concretização desse artigo, que se trata de um panorama sobre os atos empreendidos num período recente, Julho2009 a julho2010. Este levantamento confere a oportunidade de auto-avaliação sobre as metodologias que estão sendo aplicadas, da mesma forma que torna transparente à comunidade acadêmica as iniciativas que se engendram no centro de Memória do Departamento de Educação Física da Universidade Federal do Paraná, denominado CEMEDEF-UFPR.

Desenvolver alternativas para a preservação da memória escolar, aliada a perspectiva de contribuir na formação de profissionais críticos na área da educação, são os norteadores das intervenções concebidas no CEMEDEF-UFPR. Dessa maneira, o objetivo desse artigo é decompor analiticamente algumas iniciativas para localizar e responder quais atividades tem ocorrido no centro, além de refletir sobre suas conseqüências, no sentido de ressignificar a pesquisa histórica no currículo do curso superior de Educação Física.

A importância da memória estudantil, as abordagens históricas dentro do campo epistemológico da Educação Física, as políticas públicas que favorecem os usos dos arquivos, as rotinas de um centro de documentação, as possibilidades transdisciplinares, o currículo das licenciaturas, são alguns dos pontos que se pretendem discutir para reavaliar as propostas que estão hoje contidas no CEMEDEFUFPR, assim como contribuir na produção de conhecimentos que fomentem a formação de novos centros de memória e documentação escolar.

\section{Caminhos metodológicos}

A metodologia utilizada para compor esse ensaio foi a de analisar o nosso próprio dia a dia no CEMEDEF-UFPR, visando melhorar a execução de nossas ações práticas. O que para Lewin (1946), Corey (1953), Freire (1970, 1982), Schön (1983) Selener (1997), Kincheloe 
(1997), Demo (2000) e Barbier (2003) poderia ser entendido como uma pesquisa participativa, aquela que não nega estar imersa em ideologia, porém não permite que esse aspecto interfira no rigor do método científico. A intencionalidade percorria uma circularidade que passa pelas tarefas de planejamento, implementação, descrição e avaliação. Conforme o que é delineado por Brown e Dowling (2001, p. 152), conceituando pesquisa-ação como "[...] projetos em que os práticos buscam efetuar transformações em suas próprias práticas $[\ldots] "$.

Muito se assemelhou, em suas categorias de análise, àquelas inicialmente indispensáveis para a formação do centro de documentação. Basicamente analisou-se qual o atual objetivo do CEMEDEF-UFPR: universo; recorte temático; nível de especialização, e elaboraram-se algumas perguntas norteadoras: quais os atuais fundos de arquivo? Qual a atual estrutura organizacional: tratamento documental; conservação; pesquisa e divulgação; e demandas administrativas? Qual a relação do CEMEDEF-UFPR com o currículo do curso superior em Educação Física ofertado pela universidade? Quais são as características de atuação do CEMEDEF-UFPR?

Foram pesquisadas as leis, decretos e portarias referentes aos regimentos internos do DEF-UFPR. Esta tarefa permitiu a definição de prioridade para a realização das intervenções, bem como forneceu ao aluno-pesquisador o contato preliminar com as tarefas realizadas pelos setores aos quais se referiam os documentos que iriam analisar. Segundo o que é indicado por Bastos e Garcia (1999) o desenvolvimento das politicas documentais só acontece por meio da participação dos agentes presentes em organismo públicos e privados, que readequam suas ações sobre os documentos de maneira que os mesmo sejam entendidos como bens culturais.

Os métodos utilizados estavam em conformidade com as implicações técnicas estabelecidas pelo Conselho Nacional de Arquivos (CONARq), instituição que faz parte do Arquivo Nacional, considerando como documento de arquivo o que foi produzido ou 
recebido por orgão de natureza pública ou ainda particular, que constituam em sua existencia, prova de ações realizadas no exercicio das atividades da instituição em questão.

Conforme indicações ainda do CONARq, é necessário racionalizar a guarda documental para conseguir democratizar de fato o acesso aos bens documentais produzidos, gerando aspectos positivos como: acessar a informação com maior facilidade; diminuir o volume documental; garantir que se conservem os documentos permanentes; acompanhar a produção documental, utilizando suportes adequados ao registro das informações; otimizar espaço físico para arquivamento; e garantir a proteção do patrimônio arquivístico.

Norteado pela teoria das três idades, os documentos da fase corrente são avaliados, objetivando a distinção dos documentos que serão permanentente protegidos, daqueles que serão descartados.

\section{MEMÓRIA COMO SUBSÍDIO PARA A CONSTRUÇÃO dO CONHECIMENTO}

A memória constitui uma representação do passado a partir da perspectiva de um determinado grupo social. Os elementos que a sustentam erguem-se sobre a inter-relação existente entre a intencionalidade e o posicionamento de tal grupo na organização da sociedade. Como define Sears (1988), em toda sociedade, existe uma sustentação de dois grupos em oposição: o legítimo, ou endogrupo, e o ilegítimo, ou exogrupo, sendo as diferenças entre eles a responsável pelas manifestações de defesa das características de cada um dos agrupamentos sociais, o que quer dizer que a ameaça da não preservação das crenças, hábitos e costumes, através da inclusão de valores vindos de fora, irá impulsionar o compromisso de defender as características daquela sociedade no decorrer do tempo. É esclarecedor reforçar esse conceito com a ideia elisiana ilustrada por Elias e Scotson (2000), em Estabelecidos e Outsiders: 
[...] o fato de os habitantes do loteamento não agirem de acordo com os dogmas da aldeia era uma das razoes pelas quais os aldeões desdenhavam deles e os excluíam ao máximo de seu circulo. (ELIAS, SCOTSON, 2000, p. 224).

Recontar fatos e práticas e posteriormente dar a elas significado sócio-cultural é descrever as demandas de um recorte social, o qual foi continuamente atravessado por interesses, deflagrando aproximações e embates. Sendo assim, a memória torna-se visivelmente seletiva, excluindo e descartando aspectos que validam os pressupostos de cada grupo.

Em meio ao ambiente epistemológico da Educação Física, são priorizadas na maior parte das vezes as investigações e iniciativas que contribuam para a elucidação de um corpo biológico. Mais ainda, um corpo biológico que deve estar alinhado com os avanços da tecnologia, oferecendo cada dia melhor desempenho, comportando um maior número de informações, e mais convencionado a uma integração global. É uma lente que não permite visualizar os processos que dividem, analisam, classificam e modelam o corpo dos sujeitos, pois as intervenções tornam-se movidas pela busca de resultado, que normalmente é atender as expectativas do sistema pelo qual os corpos são submetidos e educados mesmo que de forma dolorosa. Como nos mostra:

Acreditamos que o curriculo de formação em Educação Física se relaciona historicamente, com o processo de construção da area acadêmica brasileira, tanto pela influencia norte-americana quanto europeia. Sabemos também que o conhecimento vindo dos ramos das ciências da natureza como a anatomia, a biologia, a fisiologia e a biomecânica fundamentaram o pensar e o agir da Educação Física no Brasil. Nesse sentido, a Educação Física brasileira teve como base de intervenção pedagógica o conhecimento produzido hegemonicamente pelo modelo biomédico e criou sua representação social a partir das ideias de higiene, eugenia, exercitação do corpo e do esporte, desde a década de 30 do século $\mathrm{XX}$ e ainda hoje existem resquícios dessa tendência. (BRUGNEROTTO, 2008, p. 47)

Movimento, Porto Alegre, v. 19, n. 03, p. 235-255, jul/set de 2013. 
Dessa maneira, entende-se que é extremamente importante dar relevância às pesquisas e intervenções que provoquem no acadêmico a percepção de que a Educação Física pode ser experimentada no presente, realizando o debate crítico acerca do que está ou esteve legitimado no percurso dessa disciplina dentro do sistema educacional. Ainda é possível compreender quais processos advindos de fora da cultura escolar influenciam nossas práticas dentro da escola, ressignificando a existência de diversas atividades constantes do currículo. Logo, incentivar o acadêmico a adentrar em caminho, que dentro da lógica dominante de produtividade, parece inverso ao que se faz tendência, permite semear novos paradigmas acerca da atuação do professor de Educação Física e das vivências experimentais pelos alunos.

Existe desde 1991 a Lei Federal no 8159 que corrobora para uma validação das práticas de conservação, preservação e restauração do patrimônio cultural brasileiro. Dentro desse espectro incluem-se diversas frentes de atuação, sendo umas delas a preservação de documentos públicos. Os arquivos escolares são um generoso campo no que ser refere a um patrimônio cultural produzido para o nivelamento das práticas sociais. Oferece um vasto corpus documental que pode responder como se deram as intervenções pedagógicas dentro dos muros de cada escola. Conforme a ideia de Nora (1993, p.13) não sendo a memória espontânea, é necessario criar os lugares da memória, como os arquivos, os lembretes de aniversários e demais celebrações, haja vista que essas atitudes não são naturais, mas construídas.

Para fins administrativos, segundo o CONARQ, o arquivo pode permanecer em sua fase corrente pelo período em que a consulta se faz mais frequente, sendo esse uso de aproximadamente cinco anos, tempo o qual a estrutura da gestão escolar depende da organização desses arquivos. Também é nesse período que normalmente essa demanda representa algo de valor para a instituição. A fase que se segue é considerada arquivo público permanente, de valor histórico, porém é erroneamente denominada muitas vezes de arquivo morto 
e tratado com o mesmo descompromisso, quando os documentos não raro são retirados de seus abrigos junto às coordenações e secretarias e lançados a outros locais para dar espaço a novos registros. Evidentemente que toda preocupação e cuidado que existia no período corrente, com a preservação de dados que comprovassem as atividades escolares, deixa na maioria das vezes de existir, como se aquele montante já tivesse cumprido a sua função. É nesse momento que se fazem necessários profissionais e políticas públicas que articulem a guarda e a posterior disponibilização para consulta de tais acervos, valorizando a memória da vida estudantil e fomentando a pesquisa sobre a cultura escolar e suas relações com a sociedade. Assim é possível entender que:

A finalidade dos arquivos escolares é a comprovação do direito da pessoa ou da administração. As informações provenientes desses arquivos são utilizadas pelos orgãos da administração pública para exercer um controle do fluxo referente ao oferecimentode vagas, matrículas, aprovação, reprovação, evasão etc. Para além dos fins comprobatórios ou burocráticos, os arquivos escolares têm valor historico e cultural, na medida em que permitem apreender elementos das praticas administrativas e pedagógicas construidas ao longo do tempo de funcionamento da escola. (LEITE, 2008 ${ }^{1}$ )

São pertinentes para tais análises aspectos da rotina da escola, como: a produção de documentos; a organização de gestão, as mudanças de norteadores pedagógicos, as influências políticas sobre sistema educacional, as manifestações docentes e/ou discentes, e por fim o gradiente de entendimento que pode ser encontrado, nas diversas escolas, a respeito da importância de serem mantidas sob tutela segura as marcas, que dialeticamente, imprimiram suas atribuições aos envolvidos na escola e, ainda forma marcadas pela atividade de seus elementos.

'Disponível em: http://www.pucpr.br/eventos/educere/educere2008/anais/pdf/114_55.pdf . Acesso em: 15 mar. 2011.

Movimento, Porto Alegre, v. 19, n. 03, p. 235-255, jul/set de 2013. 


\section{Arquivos e suas fases}

A etapa corrente dos arquivos escolares, onde são a eles atribuídos caracteres funcionalistas, é na grande parte das escolas muito bem organizada. Trata-se de um facilitador na busca e consulta de informações, sendo a ele reservado espaço junto a secretarias e estando sob a responsabilidade dos funcionários alocados nesse departamento. É por conceito algo repleto de utilidade prática. Nesse momento, parece desnecessário questioná-lo, pois o máximo que as prerrogativas que o interpelam, concebem é que poderão obter dados quantitativos. Percebe-se que ocupa lócus fundamental dentro do aparato escolar, mas ao passo que registra fatos de sujeitos que podem ainda estar envolvidos com a escola, não recebe a investida crítica sobre sua constituição e seu conteúdo. Ampliando esse pensamento com a consideração a seguir:

À medida que a informação arquivística torna-se menos utilizada ao longo do processo decisório, tende-se a eliminá-la ou conservá-la temporariamente. (JARDIM, 1995. p 13)

A fase seguinte, que varia de uma instituição para outra, mas que entra em vigor aproximadamente cinco anos após a produção do documento, é a fase do arquivo permanente. Destina-se a esse arquivo o que não tem mais utilidade administrativa. Considerada em vários casos como restos, a primeira agressão pela qual sofrem os fundos de documentos é a exposição a fatores de insalubridade e contaminação, junto a espaços inadequados para tal. A degradação de tais peças se intensifica a medida que permanecem sob tal prejuízo por tempo prolongado, diagnósticos de importantes arquivos públicos estaduais denunciam que em certos casos há comprometimento total dos documentos. Como nos conta Walter Benjamim (1989), juntar esses "restos" cumpre a tarefa silenciosa, anônima, mas imprescindível do narrador autêntico, de saber das honras e das desonras. Outro caminho percorre a escola que planeja a guarda de seu arquivo não corrente, porém não o disponibiliza para a consulta 
pública, muito menos envolve professores e alunos em seu gerenciamento. Ambas as perspectivas não desenvolvem o potencial de elucidação que estão presentes nos acervos escolares.

Em que campo, haveria condições tão propícias a um levantamento sobre o que efetivamente se consolida, através das abordagens da escola, que não seu próprio arquivo? Qual suporte serviria de repositório para o registro e pesquisa das características da cultura escolar, se não o que já contém as informações produzidas pelos seus próprios atores sociais? O alto valor sociocultural vigente nessas massas de fontes, aparentemente sem vida, mas que carregam em si detalhes das relações humanas ocorridas a partir da escola pode ser o viés mais autêntico para desvendar os engendramentos filosóficos nos quais a instituição se alicerçou. Iniciativas frutíferas tem se apresentado em outros centros de documentação e memória vinculados a universidades, como cita Goellner (2006, p. 83-84):

[...] o Centro de Memória do Esporte da Escola de Educação Física da Universidade Federal do Rio Grande do Sul - CEME - ; o Centro de Memória da Escola de Educação Física e Desportos, vinculado à Escola de Educação Física da Universidade Federal do Rio de Janeiro (2001); O Centro de Memória da Educação Física - Universidade Federal de Minas Gerais - CEMEF- UFMG (2001); e o Arquivo Maria Lenk que opera sob-responsabilidade da Biblioteca da Pós Graduação em Educação Física da Universidade Gama Filho.

\section{História No CURRÍCULO dOS CURSOS SUPERIORES DE EDUCAÇÃO Físıca}

A disciplina de História pode e deve envolver as demais disciplinas constantes da grade escolar, no sentido de ressaltar as mudanças ocorridas nas teorias do pensamento que modificam e transformam os conteúdos dos escolares. As ciências da vida, da terra, da linguagem e da área de exatas e tecnologias, embora 
pareçam compartimentar algo fechado em si mesmo, possibilitam lançar sobre elas um olhar histórico onde sejam descobertos os percursos da construção de tais conhecimentos. A Educação Física se faz parceira da investigação histórica a partir do momento que se torna inteligível o uso do corpo para variados fins educacionais, seja dentro do âmbito escolar ou fora dele. Os professores podem atribuir a seus planejamentos, pontos de intersecção que envolvam os alunos na problematização de como os discursos epistemológicos se instauram em sociedade. A história que se constrói entre a cultura escolar e o que advém de fora dela assegura a consolidação de uma história cultural que deve ser problematizada em sala de aula, conforme Forquin (1993, p.14):

[...] a cultura é o conteúdo substancial da Educação, sua fonte e sua justificação última; a Educação não e nada for a da cultura e sem ela; dir-se-á que é pela e na Educação, através do trabalho paciente e continuamente recomeçado de uma tradição docente, que a cultura se transmite e se perpetua: a Educação realiza a cultura como memória viva, reativação incessante sempre ameaçada, fio precário e promessa necessária da continuidade humana.

\section{CEMEDEF-UFPR}

No Departamento de Educação Física (DEF) da Universidade Federal do Paraná, desde 2004, vem se articulando um espaço de aglutinação para a preservação da memória. Sob a coordenação da Professora Vera Moro, organizou-se a receptação de matérias oriundos da Antiga Escola de Educação Física e Desportos do Paraná, entidade privada, pioneira na oferta dos cursos normal e superior em Educação Física no estado. Processos de estadualização e posterior, federalização, acabavam por agregar tal curso à estrutura da UFPR, em 1977. Seus registros documentais ficaram alojados em uma pequena sala no próprio departamento (DEF), até que uma iniciativa da professora acima citada levantasse a possibilidade de tomar aquela demanda documental um centro de documentação, ou como é conhecido, o Centro de Memória do Departamento de 
Educação Física - (CEMEDEF-UFPR). Muito semelhante ao que foi conceitualmente descrito como centro de documentação por Tessitore (2003), "entidade híbrida", que reúne características de museu, biblioteca e arquivo ${ }^{2}$.

O vínculo do CEMEDEF-UFPR com o departamento se dá a partir do Centro de Pesquisas em Esporte, Lazer, Sociedade (CEPELS), todavia sua gestão é autônoma, recebendo e organizando materiais tanto da antiga escola, quanto do atual departamento. A UFPR recorre a ele, no que se refere às funções administrativas de um arquivo, quando são necessárias consultas a documentos de diversas ordens, como atestados, diplomas, certificados, solicitados normalmente para alguma comprovação profissional. Já no que se refere à pesquisa, o centro é procurado por profissionais de diversas áreas para a verificação de dados que embasem suas análises.

O grande impedimento que tem cerceado um melhor desenvolvimento do CEMEDEF-UFPR tem sido a falta de recursos. Por tratar-se de em espaço de restauração e conservação de fontes históricas, requer um rol de materiais que contemplem a execução de tarefas técnicas de tratamento. Devido ao tempo de produção desses documentos já ser bem avançado, necessitam de cuidados diferenciados que minimizem os efeitos degradativos que incidem sobre eles, como o uso de caixas arquivos que não permitem a ação da umidade e da luz, clipes revestidos que não catalisem oxidação, iluminação adequada e equipamentos de proteção individual para os pesquisadores. Além disso, fica reduzida a oportunidade de apresentar o trabalho que acontece no CEMEDEF-UFPR em eventos, prejudicando não só o compartilhamento de nossas pesquisas, mas principalmente o intercâmbio de diferentes métodos e abordagens que se desenvolvam em outros centros de documentação estudantil.

Atualmente estão ligadas ao CEMEDEF-UFPR a disciplina de História da Educação Física e as quatro etapas do módulo de

\footnotetext{
${ }^{2}$ Conforme Tessitore (2003) em 'Como implantar centros de documentação?', um museu possui objetos tridimensionais e/ou tem função colecionadora e/ ou tem função recreativa e/ou referencia peça a peça; a biblioteca possui documentos originados da cultura e da pesquisa cientifica e/ou tem finalidade educativa e ou/ faz referencia a peças isoladamente; e o arquivo se origina de uma acumulação orgânica, administrativa e possui peças seriadas.
} 
Projetos Integrados. Ambas são ministradas pelo Professor André Mendes Capraro, também atual coordenador do CEMEDEF-UFPR. Em História da Educação Física, disciplina constante do primeiro ano do curso, os alunos conhecem os conceitos bases de fonte histórica e de memória, escolhem uma temática que lhes agrade e desenvolvem uma pesquisa,. No formato de artigo, com os resultados da investigação. Nos Projetos Integrados, são oportunizados as vivências práticas no centro de documentação, do mesmo tempo que debatem-se as possibilidades de pesquisa que podem surgir do acervo.

Além do coordenador do núcleo, colabora na organização das rotinas do CEMEDEF-UFPR, uma equipe de bolsistas e voluntários, composta por doze pessoas. É estabelecida uma escala de revezamento de horários e tarefas, de modo que nenhum participante fique sobrecarregado de atividades técnicas, e possam dedicar o tempo de permanência no local para a construção de novos conhecimentos, através do surgimento de questionamentos.

Todas as propostas didáticas pedagógicas inseridas nas atividades do CEMEDEF-UFPR objetivam despertar no acadêmico do curso de licenciatura, uma reflexão profunda sobre como utilizar a História como ferramenta de aprendizagem. As práticas da Educação Física, atravessadas pelo uso dos métodos de adestramento corporal, não devem ser reproduzidas por si só, ausentando o carater histórico-filosófico que as regem. $\mathrm{O}$ acadêmico participa ativamente de todas as fases do processo de preservação dos documentos, conhecendo métodos flexíveis que possam oferecer soluções aos mais diversos diagnósticos encontrados nas escolas. Por fim (o que se considera, dentro do atual objetivo de trabalho do CEMEDEFUFPR, ser o resultado mais valioso) despertar o interesse pela valorização do patrimônio cultural produzido pela dimensão educacional da sociedade, e partindo desse eixo, elaborar novas compreensões, decodificando-as na forma de pesquisa. Silvana Goellner (2005) colabora muito para a compreensão desse universo: 
Vale lembrar que a história enquanto área de produção do conhecimento pode qualificar de forma inequívoca os estudos desenvolvidos acerca do esporte moderno visto que ao rememorar o passado pode colaborar para a compreensão do presente e quem sabe, ajudar na projeção do futuro. (GOELLNER, 2005, p. 80)

Tanto na disciplina de História da Educação Física quanto na de Projetos Integrados, antes de qualquer intervenção, o primeiro passo é fornecer os protocolos de arquivamento para documentos e demais materiais históricos, na forma de capacitações moduladas. O conteúdo é dividido em três partes, sendo que em cada uma delas, além de apresentadas e discutidas em grupo, é encaminhada para o correio eletrônico pessoal de cada aluno. São abordados conteúdos básicos e intermediários para a gestão documental, haja vista que uma formação mais consistente e avançada só poderia ser conduzida por um especialista da área. Os instrutores são voluntários e participam continuamente de atualizações formativas, junto a órgãos oficiais, como o Arquivo Público do Estado do Paraná, a própria UFPR, entre outras.

A intenção é oferecer subsídios metodológicos para que cada aluno consiga se necessário, organizar um centro de documentação de maneira simples. Em seguida começam a serem sugeridas algumas leituras, cujas discussões são realizadas em grupo. A constituição da memória, a preservação do patrimônio sociocultural, as experiências compartilhadas por outros centros de documentação, são alguns dos elementos mais problematizados. Os acadêmicos têm em média duas semanas para leitura do texto, sendo que durante cada semestre letivo são discutidos no mínimo quatro textos. Dessa forma compreende-se que ele estará intensamente envolvido na reflexão sobre a finalidade de um centro de memória escolar. Além disso, o CEMEDEF-UFPR mantém atualizada uma pasta com outros textos na copiadora do departamento, tornando fácil e barato o acesso aos conteúdos pertinentes ao aprofundamento teórico. 
O manejo do acervo só se dá após esse primeiro entendimento de passos importantes para a organização das rotinas de um centro de documentação. É nesse momento que são demonstrados a técnicas de higienização, classificação, guarda e indexação do arquivo. Procura-se dividir a turma em quatro frentes de atuação que seguem um rodízio: Biblioteca da antiga escola; acervo da antiga escola; acervo dos professores; e acervo das atividades desenvolvidas em cada frente varia conforme a necessidade do centro naquele momento, fazendo dos acadêmicos protagonistas da ação de preservação. Todavia não são delegados aos alunos tarefas em excesso, já que o objeto maior é proporcionar a eles o contato com as fontes, a observação criteriosa das mesmas, assim como a possível vontade de pô-las à prova.

Uma iniciativa que obteve bons frutos iniciou no segundo semestre de 2009 e que perdurou no primeiro semestre de 2010 e a captação de bibliografias junto aos professores atuantes no DEF. Cada aluno recebeu um ofício, que informava sobre a doação de bibliografias e demais matérias relativas à atividade docente, e então selecionou professores para contatá-los a fim de intermediar essa receptação em nome do CEMEDEF-UFPR. A coleção do acervo dos professores foi significativamente ampliada, permitindo novas indagações, agora sobre a formação intelectual dos docentes do DEF.

Diante de condições favoráveis ao segmento do pensamento crítico, habilita-se ainda a concretização da produção do conhecimento. Artigos, monografias, teses e dissertações têm sido orientadas em função do acervo disponibilizado pelo CEMEDEFUFPR, que cumpre por sua vez o lugar privilegiado de banco de pesquisas. Obviamente que por localiza-se em um ambiente de tamanho reduzido, não é possível prestar atendimento a muitos pesquisadores do mesmo tempo, mas é possível agendar um horário para verificar o corpus documental. Não são permitidas fotocópias de documentos com mais de dez anos de produção, sendo nesse caso uma alternativa o registro fotográfico dos materiais.

Na mesma vertente da produção de saberes que contemplem a significação das práticas de preservação histórica, procura-se 
participar de eventos que tematizem essa área de ação e que reúnam pesquisadores e profissionais comprometidos com a valorização da memória. Estabelecer uma ponte que propicie o diálogo, fomente as possibilidades de acerto na constituição de nossos espaços com essas finalidades. A barreira que tem se tentado transpor é a da limitação financeira, em especial a destinada aos translados, hospedagens e inscrições para participação.

\section{Evidencias PARA AUtO-AVALIAÇÃo}

A maior resposta que se é possível obter a partir do envolvimento na consolidação de um centro de memória escolar é perceber que pode ser abrigo para o debate construtivo entre as epistemes distintas que se fazem presente e exercem forças muitas vezes concorrentes, dentro da escola. O novo olhar é proporcionado ao acadêmico que, além de toda experiência corporal prática presente no curso de Educação física, pode intervir na formação da memória, na explicitação de processos históricos e na significação da existência deste tipo de espaço junto aos núcleos estudantis e de professorados onde forem atuar. Ou seja, não será na reprodução o que se faz na disciplina de Projetos Integrados, na escola em que atua que o CEMEDEF-UFPR estará cumprindo um de seus objetivos essenciais, mas sim quando o acadêmico enunciar questionamentos críticos, e conseguir planejar a formação de um centro de documentação, levando em consideração os aspectos contextuais que o tornam único. Tendo principalmente o entendimento de que é indispensável o trabalho em equipe, indivíduos que colaboram na estruturação do grupo social referido.

A individualidade, tão afrmada no mundo contemporaneo, alimenta-se de um patrimonio comum que nos condiciona em varios aspectos e partilha, em grau variável, um conjunto de referentes. Os acontecimentos passados, inscrevem as suas marcas no espaço físico, social, cultural, bem como na corporeidade e na consciencia individual. São esses vestigios que tornam possivel revisitar o passado e constituir cadeias temporais que

Movimento, Porto Alegre, v. 19, n. 03, p. 235-255, jul/set de 2013. 
estruturam a percepção e a memoria, uma vez que o passado, está inacessível (FELGUEIRAS, 2005,p16)

Por fim, ao concordar com uma perspectiva sobre o corpo que prediz ser ele necessário para toda e qualquer aprendizagem, seja essa de aspecto estritamente físico, ou de ordem intelectual, podendo ainda combinar características de cada grupo, é reforçada a interdisciplinaridade da abordagem aqui descrita e proposta.

À medida que a multiplicidade de determinações
que marcam o corpo dizem respeito à forma pela
qual o homem se relaciona com o meio físico e com
os outros homens, e ainda às formas assumidas
historicamente por essas relações, o corpo anátomo-
fisiológico, aparece com um corpo investido
socialmente. (DONNANGELO; PEREIRA, 1979,
p 25)

Foi possível evidenciar durante o primeiro semestre de 2010, o caráter investigativo onde está cunhado o planejamento das disciplinas de Projetos Integrados orientadas no CEMEDEF-UFPR. Até então, no final de cada semestre letivo era solicitado ao aluno um relatório de atividades, que poderia ser escrito em formato de artigo. Todavia, pensa-se que apenas enumerar as execuções técnicas que foram realizadas não basta para vincular a pesquisa histórica a um centro de memória. Apostando no potencial observado de cada um dos alunos, que demonstraram ter apreciado o contato com as fontes históricas, foram sugeridas três atividades distintas, podendo o aluno livremente optar por umas delas, assim como definir o tema abordado. A opção de escrever um artigo foi mantida e, como produto foram construídos textos, os quais referenciam documentos e bibliografias do acervo do CEMEDEF-UFPR, problematizando principalmente a história do esporte e dos centros de documentação escolar. A segunda opção foi à confecção de um cartaz, do tipo banner, sendo essa a proposta, causou mais adesão por parte dos alunos, tendo a maioria dos trabalhos com temáticas gerando girando em torno de análises do esporte conforme a perspectiva da primeira revista da área da Educação Física no Brasil, assim como levantamentos de 
campeonatos organizados pelos próprios estudantes do DEF. A terceira opção sugerida foi à elaboração de uma apresentação, com duração entre 15 e 25 minutos, apresentada ao grupo. Essa última opção foi desenvolvida por apenas um aluno, tendo esse feito um mapeamento das corridas, nas mais diversas categorias, a partir da ótica da Revista Educação Physica, coleção que está presente em nosso acervo bibliográfico. Paralelamente aos trabalhos realizados pelo grupo de alunos, outros dois desses, os quais possuíam um conhecimento avançado da informática, trabalharam na digitalização de fichas documentais, digitalização de fotografias e desenvolvimento de um sítio para discussões na internet.

Edificar tangentes temáticas entre os planos dos professores apresenta-se como uma das alternativas para consolidar uma aprendizagem mais contextualizada. A Educação Física não deve abster-se de propiciar reflexões sobre um novo intervir, que agregue ações transformadoras, compreendido em função do esclarecimento de discursos e práticas que se enraizaram no passado. Isso se ressignifica em uma sociedade, como a compreendida por Moro e Godoy (2006), da 'novidade', onde os saberes adquiridos no processo histórico são sublimados pela quantidade de informação que se tem produzido.

O CEMEDEF-UFPR atualmente oferece acesso ao acervo sob agendamento, por motivo de estar em espaço físico limitado. $\mathrm{O}$ corpus documental é composto pelo Acervo da Biblioteca da Escola de Educação Física e Desportos do Paraná, Acervo da Escola Normal e Superior de Educação Física e desportos do Paraná, acervos dos Professores de Educação Física (antiga escola e DEF - UFPR) e Acervo do Centro Acadêmico de Educação Física. Estão sob a tutela do CEMEDEF e classificados nos arquivos acima citados documentos, materiais esportivos, uniformes, fotografias, gravações de imagem (em formato super 8, VHS, microfilme, CD e DVD), livros, manuais, revistas e textos diversos. Há registros que comprovam a fundação de uma escola que usava a educação do corpo, principalmente para atender as demandas do mercado profissional que já estava em andamento, assim como tornar restrito aos que possuíssem formação. 


\section{ConsideraÇões Finals}

A constituição de um centro de documentação acadêmica tornou-se hoje uma das principais ferramentas para a pesquisa em história da educação física no DEF-UFPR. Disponibiliza subsídios para a reflexão de processos educacionais, além de envolver a própria comunidade produtora de tais desdobramentos. Se orienta em razão da premissa de que para existência de um centro de documentação, além do objetivo inicial de preservar a memória institucional é ainda mais significativo valorizar as abordagens que problematizam os acontecimentos históricos. A possibilidade de se obter diferentes respostas através da pesquisa histórica, em relação aos discursos dominantes, tidos como verdades absolutas, amplia os horizontes de quem está envolvido diariamente no fazer pedagógico.

Constatamos a partir da relação estreita que se estabeleceu entre o currículo do ensino superior em educação física, com as atividades de um centro de memória, que o processo pedagógico foi enriquecido, pois, viabilizou intervenções interdisciplinares, que não só facilitaram a aprendizagem, mas ainda provocaran aproximações entre os diversos estratos organizados dentro da instituição da qual fazemos parte. 
The preservation of student's memory like a curriculum proposal in the Physical Education Undergraduate University: the CEMEDEF'S case (Physical Education Department- Paraná Federal University)

Abstract: Intervening in preserving the memory is not just school performing technical tasks, although such actions are necessary in the space of valuation cultural of heritage produced by educational institutions. Is essential cover in planning for the establishment of documentation centers, the relationship with the teaching practice and the student experience. It is these actors that produce the events of the school culture and should be responsible for the safekeeping and preservation of the landmarks that have been printed in memory of the context where they it settled. Based on this premise, this article points to alternatives that are being developed in CEMEDEF-UFPR (Center Memory of the Department of Physical Education), so that interventions can be assessed or even subsidize proposals for the establishment of new centers of documentation of school.

Keywords: Memory.School. interdisciplinary.

La preservacion de la memoria de los estudiantes como una propuesta curricular de los cursos de Educacíon Superior en Educación Física

Resumen: Intervenir en la preservación de la memoria escolar no es solo realizar tareas técnicas, aunque esas acciones sean necesarias en un ínterin de valoración del patrimonio cultural producido por las instituciones escolares. Es esencial comprender el planeamiento para la constitución de centros de documentación, la relación con la práctica docente y la vivencia dicente. Son estos los actores que producen los acontecimientos de la cultura escolar y deben ser los responsables por guardar y conservar los marcos que fueron impresos en la memoria del contexto en donde se establecieron. Fundamentados en esa premisa, este artículo pretende apuntar alternativas que son desarrolladas en CEMEDEF-UFPR (Centro de Memoria del Departamento de Educación Física), para que las intervenciones puedan ser evaluadas o hasta subsidiadas propuestas para la fundación de nuevos centros de documentación escolar.

Palabras clave: Memoria. Escuela. Interdiscipli nariedad 


\section{REFERÊNCIAS}

BARBIER, R. A pesquisa-ação. Brasília: Plano, 2002.

BASTOS, Isabel; GARCIA, Maria Madalena Moura Machado. A gestão dos documentos: balanças e perspectivas. Cadernos BAD, Lisboa, n.2, p.93-106,1992.

BENJAMIM, Walter. Obras escolhidas. Trad. modificada de José Carlos Martins Brabosa. São Paulo: Brasiliense, 1989.

BRASIL. Lei n. 8.159, de 8 de janeiro de 1991. Dispõe sobre a política nacional de arquivos públicos e privados e dá outras providências. Diário Oficial, Brasília, 9 jan. 1991.

BROWN, A.; DOWLING, P. Doing research/reading research: a mode of interrogation for teaching. Londres: Routledge Falmer, 2001.

BRUGNEROTTO, Fábio A. Caracterização dos currículos de formação profissional em Educação Física: um enfoque sobre a saúde. Diss de mestrado da Faculdade de Ciencias da Saúde da Universidade Metodista de Piracicaba, 2008.

CONARq. Conselho Nacional de Arquivos. Classificação, Temporalidade e Destinação de documentos de arquivos relativos as atividades-meio da administração pública. Rio de Janeiro, 2001.

CONSELHO INTERNACIONAL DE ARQUIVOS. ISAD(G): norma geral internacional de descrição arquivística. 2. ed. Rio de Janeiro : Arquivo nacional, 2000.

COREY, S. M. Action research to improve school practices. Nova York: Teachers' College, 1953.

DONNANGELO, M. C. F.; PEREIRA, L. Saúde e Sociedade. 2. ed., São Paulo: Duas Cidades, 1979.

ELIAS, Norbert; SCOTSON, John L. Os estabelecidos e os outsiders: sociologia das relações de poder a partir de uma comunidade. Trad Vera Ribeiro. Rio de Janeiro: Jorge Zahar, 2000,

FELGUEIRAS, Margarida L. . Materialidade da cultura escolar. A importância da museologia na conservação/comunicação da herança educativa. Pró-Posições, Campinas, v. 16, n. 1, p. 87-102, 2005.

FORQUIN, Jean-Claude. Escola e Cultura: bases epistemológicas do conhecimento escolar., Porto Alegre:Artmed, 1993.

FREIRE, Paulo. Pedagogia do oprimido. New York: Herder \& Herder, 1970.

FREIRE, Paulo. Sobre a educação. Rio de Janeiro: Paz e Terra, 1982. v. 1. 
GOELLNER, Silvana V. Locais de memória: histórias do esporte moderno. Arquivos em Movimento, Rio de Janeiro, v. 1, n. 2, p. 79-86, jul./dez. 2005.

JARDIM, José M. A invenção da memória nos arquivos públicos. Ciência da Informação, Rio de Janeiro, v. 25, n. 2, 1996. Disponível em:http://revista.ibict.br/ ciinf/index.php/ciinf/article/view/439/397. Acesso em: 18 mar. 2011.

KINCHELOE, J. L. A formação do professor como compromisso político: mapeando o pós moderno. Porto Alegre: Artes Médicas, 1997.

LEITE, Lilian I. Arquivo morto ou arquivo histórica-educacional: qual o lugar da memória da/ na escola? Disponível em: http://www.pucpr.br/eventos/educere/ educere2008/anais/pdf/114_55.pdf :. Acesso em: 15 mar. 2011.

LEWIN, K.. Action research and minority problems. Journal of Social Issues, Malden, n. 2, p. 34-36, 1946.

MORO, Vera L.; GODOY, Letícia. Centros de Memória em Educação Física, Esporte e Lazer: algumas contribuições para o debate. In: CONGRESSO NACIONAL DE HISTÓRIA DO ESPORTE, LAZER, EDUCAÇÃO FÍSICA E DANÇA, 10. Curitiba: UFPR, 2006.

NORÁ, Pierre. Entre memória e História: a problemática dos lugares. Revista do Programa de Estudos Pós-graduados em História, São Paulo, n. 10, p 7-29, 1993.

SCHÖN, D. The reflective practitioner: how professionals think in action. Nova York: Basic Books, 1983.

SEARS, D. HENRY, P. J.. Origins of symbolic racism. Journal of Personality and Social Psychology, Arlington, v. 85, p. 259-275 1988.

SELENER, D. Participatory action research and social change: approaches and critique. Nova York: Cornell University, 1992.

TESSITORE, Viviane. Como implantar centros de documentação. São Paulo: Arquivo do Estado e Imprensa do Estado de São Paulo, 2003. v. 9.

Endereço para correspondencia:

Centro de Estudos e Pesquisas em Esportes, Lazer e Sociedade.

Departamento de Educação Física

Rua Coração de Maria, 92

Jardim Botânico.

Curitiba - Paraná

CEP 80215-370

Recebido em: 27.03.2012

Aprovado em: 16.01.2013 